\title{
Does body mass index affect the rate of adverse outcomes in total hip and knee arthroplasty? A retrospective review of a total joint replacement database
}

\author{
Irfan Abdulla, MD \\ Saboura Mahdavi, MSc \\ Hoa Khong, MD, MPH \\ Richdeep Gill, MD, PhD \\ James Powell, MD \\ Kelly Dean Johnston, MD \\ Rajrishi Sharma, MSc, MD
}

Accepted July 24, 2019

\author{
Correspondence to: \\ R. Sharma \\ University of Calgary \\ Calgary AB T2N 4N1 \\ rajrishi.sharma@ucalgary.ca
}

DOI: 10.1503/cjs.006719

\begin{abstract}
Background: Total hip arthroplasty (THA) and total knee arthroplasty (TKA) are reliable surgical options to treat pain and disability resulting from degenerative conditions around the hip and knee. Obesity is a modifiable risk factor that contributes to significant morbidity. The purpose of this study was to retrospectively compare outcomes in primary hip and knee arthroplasty for patients with increased body mass index (BMI) and those with normal BMI, using data from the registry of the Alberta Bone and Joint Health Institute (ABJHI).
\end{abstract}

Methods: We retrospectively reviewed the data compiled in the ABJHI registry between March 2010 and July 2016. We reviewed outcomes with respect to length of stay, discharge destination, 30-day readmission, postoperative infection, postoperative transfusion requirements, postoperative adverse events and in-hospital postoperative mechanical complications.

Results: A total of 10902 patients (6076 women, 4826 men) who underwent THA and 16485 patients (10057 women, 6428 men) who underwent TKA were included in the study. For both THA and TKA, patients with increased BMI had an increased number of in-hospital medical events, had an increased rate of deep infection, were less likely to be discharged home $(p<0.001)$ and had decreased transfusion requirements $(p<0.001)$ than patients whose weight was in the normal range. Increased BMI increased the rate of 30-day readmission and length of stay in the THA cohort but not in the TKA cohort. Increased BMI had no effect on acute postoperative dislocation or periprosthetic fractures. Patients with a BMI of $30 \mathrm{~kg} / \mathrm{m}^{2}$ or greater required a THA 1.7 years earlier than patients of normal weight, patients whose BMI was $35 \mathrm{~kg} / \mathrm{m}^{2}$ or greater required a THA 3.4 years earlier, and patients whose BMI was $40 \mathrm{~kg} / \mathrm{m}^{2}$ or greater required a THA 5.8 years earlier. In the TKA cohort, patients with a BMI of $30 \mathrm{~kg} / \mathrm{m}^{2}$ or greater required a TKA 2.7 years earlier than patients whose weight was in the normal range, patients with a BMI of $35 \mathrm{~kg} / \mathrm{m}^{2}$ or greater required a TKA 4.6 years earlier, and patients whose BMI was $40 \mathrm{~kg} / \mathrm{m}^{2}$ or greater required a TKA 7.6 years earlier.

Conclusion: Our study quantifies the effects of obesity in primary hip and knee arthroplasty. It provides a greater understanding of the risks in the obese population when contemplating joint arthroplasty.

Contexte : La prothèse totale de la hanche (PTH) et la prothèse totale du genou (PTG) sont des options chirurgicales fiables pour traiter la douleur et l'invalidité résultant de maladies dégénératives de la hanche et du genou. L'obésité est un facteur de risque modifiable qui contribue significativement à la morbidité. Le but de cette étude était de comparer de manière rétrospective le résultat des interventions primaires pour prothèses de la hanche et du genou selon que les patients avaient un indice de masse corporelle (IMC) normal ou élevé à partir des données du registre de l'Alberta Bone and Joint Health Institute (ABJHI).

Méthodes : Nous avons analysé de manière rétrospective les données compilées par le registre de l'ABJHI entre mars 2010 et juillet 2016. Nous avons passé en revue les paramètres suivants : durée du séjour hospitalier, destination post-congé, réadmissions dans les 30 jours, infections postopératoires, besoins transfusionnels postopératoires, complications postopératoires et complications mécaniques postopératoires perhospitalières.

Résultats : En tout, 10902 patients (6076 femmes, 4826 hommes) ayant subi une PTH et 16485 patients (10057 femmes, 6428 hommes) ayant subi une PTG ont été 
inclus dans l'étude. Tant pour la PTH que pour la PTG, les patients ayant un IMC élevé ont présenté un plus grand nombre de complications médicales en cours d'hospitalisation; ils ont aussi présenté un nombre plus élevé d'infections profondes, étaient moins susceptibles de pouvoir retourner chez eux au moment de leur congé $(p<0,001)$ et ont eu moins besoin de transfusions $(p<0,001)$ comparativement aux patients dont le poids se situait dans l'éventail des valeurs normales. L'IMC élevé a été en corrélation avec une augmentation du taux de réadmission à 30 jours et de la durée du séjour dans la cohorte soumise à une PTH, mais non dans la cohorte soumise à une PTG. L'IMC élevé n'a exercé aucun effet sur la dislocation postopératoire aiguë ou les fractures périprothétiques. Les patients ayant un IMC de $30 \mathrm{~kg} / \mathrm{m}^{2}$ ou plus ont eu besoin d'une PTH 1,7 an plus tôt que les patients de poids normal, les patients ayant un IMC de $35 \mathrm{~kg} / \mathrm{m}^{2}$ ou plus ont eu besoin d'une PTH 3,4 ans plus tôt, et les patients ayant un IMC de $40 \mathrm{~kg} / \mathrm{m}^{2}$ ou plus ont eu besoin d'une PTH 5,8 ans plus tôt. Dans la cohorte soumise à la PTG, les patients ayant un IMC de $30 \mathrm{~kg} / \mathrm{m}^{2}$ ou plus ont eu besoin d'une PTG 2,7 ans plus tôt que les patients de poids normal, les patients ayant un IMC de $35 \mathrm{~kg} / \mathrm{m}^{2}$ ou plus ont eu besoin d'une PTG 4,6 ans plus tôt, et les patients ayant un IMC de $40 \mathrm{~kg} / \mathrm{m}^{2}$ ou plus ont eu besoin d'une PTG 7,6 ans plus tôt.

Conclusion : Notre étude quantifie les effets de l'obésité sur le recours aux interventions primaires pour prothèse de la hanche et du genou. Elle permet de mieux comprendre les risques auxquels est exposée la population obèse lorsqu'une intervention pour prothèse articulaire est envisagée.

$\mathrm{T}$ otal hip arthroplasty (THA) and total knee arthroplasty (TKA) are safe and reliable surgical options to treat pain and disability resulting from degenerative conditions of the hip and knee. They have been shown to be reliably associated with improvements in overall health, quality of life and physical function. ${ }^{1-8}$

Since 1980, the number of overweight and obese individuals has doubled worldwide. Data from the World Health Organization (WHO) indicate that in 2014 more than 10\% of the adult population was obese (body mass index $[\mathrm{BMI}] \geq 30 \mathrm{~kg} / \mathrm{m}^{2}$ or $>20 \%$ above ideal body weight), and the incidence and prevalence of obesity are increasing., ${ }^{2,9}$

Obesity is a modifiable risk factor contributing to lifestyle diseases such as ischemic heart disease, stroke, hypertension, sleep apnea and diabetes. There is increasing evidence that obesity also contributes to the acceleration of degenerative joint disease., ${ }^{3,9}$ The risk of developing endstage osteoarthritis is 4- to 5 -fold higher in obese patients, and as a result they require total joint arthoplasty (TJA) earlier in life than normal-weight patients. ${ }^{10}$

The WHO classifies obesity on the basis of BMI. Normal-weight individuals have a BMI between 18.5 and $24.9 \mathrm{~kg} / \mathrm{m}^{2}$, and overweight individuals have a BMI between 25 and $29.9 \mathrm{~kg} / \mathrm{m}^{2}$. Obesity is defined as BMI greater than or equal to $30 \mathrm{~kg} / \mathrm{m}^{2}$, and it is subdivided into class I (BMI $\left.30-34.9 \mathrm{~kg} / \mathrm{m}^{2}\right)$, class II $\left(35-39.9 \mathrm{~kg} / \mathrm{m}^{2}\right)$ and class III $\left(\geq 40 \mathrm{~kg} / \mathrm{m}^{2}\right){ }^{2}$ Patients who have a BMI greater than 40 are classified as morbidly obese. There are mixed results with respect to surgical time, wound drainage, blood loss, deep vein thrombosis, length of hospital stays and rates of superficial and deep infection requiring reoperation in obese patients undergoing TJA. ${ }^{11-13}$

The purpose of this study was to retrospectively compare length of stay, complications and adverse events in patients undergoing primary hip and knee arthroplasty who had an increased BMI with results for those who had a normal BMI, using the prospectively collected data compiled in the Alberta Bone and Joint Health Institute (ABJHI) registry.

\section{Methods}

We retrospectively reviewed the data compiled in the ABJHI registry between March 2010 and July 2016. All patients who had undergone primary hip arthroplasty and knee arthroplasty were included. Hip resurfacing and simultaneous bilateral hip replacements were excluded, as were unicompartmental knee replacements and simultaneous bilateral knee replacements. Patient demographics were reviewed, and cases were grouped according to the patients' WHO weight classification (normal weight, overweight, class I obesity, class II obesity, class III obesity). Data for each group were then retrospectively reviewed, and presurgical risk factors were captured. Presurgical risk factors that were identified in the database included history of thromboembolic disease, cardiac disease, dementia or moderate or severe mental illness, chronic pulmonary dysfunction, chronic hepatic dysfunction, renal dysfunction, diabetes with complications, history of stroke and malignancy. Patients were divided into 3 groups, depending on the number of presurgical risk factors they had: 0 risk factor, 1 risk factor and 2 or more risk factors.

Postoperative data were examined for each BMI group. These data included patient outcomes with respect to length of stay, discharge destination, 30-day readmission rate, postoperative infection, postoperative transfusion requirements, postoperative in-hospital adverse medical events and in-hospital postoperative mechanical complications (dislocation or periprosthetic fracture).

As part of the ongoing provincial surgical site infection surveillance program, records on every primary, elective 
hip and knee arthroplasty were cross-linked to data in the Discharge Abstract Database (DAD) and the National Ambulatory Care Reporting System (NACRS) to identify any hospital readmission or ambulatory care visit within 6 months of surgery. ${ }^{14}$

Superficial and deep wound infections within 6 months of surgery were identified by infection control specialists as part of the provincial surgical site infection surveillance program..$^{15}$ Superficial infections include infections limited to the skin and subcutaneous tissue. Deep infections include both deep incisional and organ-space infections.

Descriptive analysis was performed on patient characteristics (age, sex and presurgical risk factors). Continuous variables were summarized as means \pm standard deviation (SD) along with the range of values, while categorical variables were expressed as numbers and percentages. We used $t$ tests to compare continuous variables and Pearson $\chi^{2}$ or Fisher exact tests to compare categorical variables.

Patients were stratified by BMI according to the WHO categorization of BMI: normal weight, overweight and obese (class I, II, III). These stratified groups were compared with respect to length of stay, discharge destination, 30-day readmission rate, postoperative infection, postoperative transfusion, postoperative medical adverse events (e.g., deep vein thrombosis, pulmonary embolism, myocardial infarction) and in-hospital postoperative mechanical complications (e.g., dislocation, fracture).

Multivariable logistic regression was used to compare the odds of a medical event, mechanical event, transfusion, 30-day readmission and deep infection as well as discharge destination (classified as "home" with or without home care or "not home," which included transfer to an acute care, subacute care or long-term care facility) between the study groups (normal weight, overweight and obese [class I, II, III]). Results were adjusted for age, sex and presurgical risk factors.

Multivariable linear regression was used to compare the acute length of stay between study groups. Results were adjusted for age, sex and presurgical risk factors.
The analysis was done for THA and TKA separately. Significance was set at 0.05 . All statistical analyses were performed with Stata version 13 software.

All of the data were deidentified by ABJHI according to the provincial health authority's deidentification standards. This study was approved by the University of Calgary's Conjoint Health Research Ethics Board.

\section{Results}

\section{Total hip arthroplasty}

The characteristics of patients who underwent THA are shown in Table 1. A total of 10902 patients who underwent hip arthroplasty were included in this study (6076 women, 4826 men). Of these patients, $82.4 \%$ were overweight or had class I, II or III obesity according to the WHO classification. The majority of these patients were men. There was an inverse relationship between age at intervention and classification of obesity $(p<0.001)$. Patients with a BMI of $30 \mathrm{~kg} / \mathrm{m}^{2}$ or greater required a THA 1.7 years earlier than patients of normal weight, patients whose BMI was $35 \mathrm{~kg} / \mathrm{m}^{2}$ or greater required a THA 3.4 years earlier than patients of normal weight, and patients with a BMI of $40 \mathrm{~kg} / \mathrm{m}^{2}$ or greater needed a THA 5.8 years earlier than patients of normal weight. Patients with class II and class III obesity were more likely to have 2 or more surgical risk factors (43.9\% and $47.4 \%$, respectively) than patients classified as being of normal weight $(38.0 \%)(p<0.001)$.

Patient BMI had no effect on in-hospital postoperative periprosthetic fracture or dislocations or on in-hospital medical events (Table 2). Patients with BMI values in the class I, II or III obesity range all had lower rates of blood transfusion $(7.8 \%, 6.7 \%$ and $6.3 \%$, respectively) than patients with a normal weight $(17.2 \%)(p<0.001)$.

Patients with class II obesity (OR [odds ratio] 1.64, 95\% confidence interval [CI] 1.19 to 2.25 ) and class III obesity (OR $1.59,95 \%$ CI 1.10 to 2.31) had higher rates of 30-day readmission than patients in other BMI classes (Table 2).

\begin{tabular}{|c|c|c|c|c|c|c|}
\hline \multirow[b]{2}{*}{ Characteristic } & \multicolumn{5}{|c|}{ Patients; weight class } & \multirow[b]{2}{*}{$p$ value } \\
\hline & $\begin{array}{c}\text { Normal weight } \\
\qquad n=2031\end{array}$ & $\begin{array}{c}\text { Overweight } \\
n=3832\end{array}$ & $\begin{array}{c}\text { Class I obese } \\
n=2896\end{array}$ & $\begin{array}{c}\text { Class II obese } \\
n=1332\end{array}$ & $\begin{array}{c}\text { Class III obese } \\
\qquad n=811\end{array}$ & \\
\hline Age, mean, yr & $67.1 I^{\prime} \mathrm{v}$ & 67.0 & 65.4 & 63.7 & 61.3 & $<0.001^{*}$ \\
\hline \multicolumn{7}{|l|}{ Sex, no. (\%) } \\
\hline Male & $545(26.8)$ & $1877(49.0)$ & $1453(50.0)$ & $611(45.9)$ & $340(41.9)$ & $<0.001 \dagger$ \\
\hline Female & $1486(73.2)$ & $1955(51.0)$ & $1443(50.0)$ & $721(54.1)$ & $471(58.1)$ & \\
\hline \multicolumn{7}{|c|}{ Presurgical risk factors, no. (\%) } \\
\hline 0 & $660(32.5)$ & $1230(32.1)$ & $901(31.1)$ & 390 (29.3) & $211(26.0)$ & $<0.001 \dagger$ \\
\hline 1 & $600(29.5)$ & 1160 (30.3) & $870(30.0)$ & $357(26.8)$ & $216(26.6)$ & \\
\hline$\geq 2$ & $771(38.0)$ & 1441 (37.6) & 1126 (38.9) & 585 (43.9) & $384(47.4)$ & \\
\hline
\end{tabular}


Table 2. Results of multivariable logistic regression for total hip arthroplasty

\begin{tabular}{|c|c|c|}
\hline Outcome; comparison & OR $(95 \% \mathrm{Cl})$ & $p$ value \\
\hline \multicolumn{3}{|l|}{ In-hospital fracture or dislocation } \\
\hline Overweight v. normal weight & 0.85 (0.52 to 1.42$)$ & 0.53 \\
\hline Obese I v. normal weight & $0.61(0.34$ to 1.10$)$ & 0.10 \\
\hline Obese II v. normal weight & 0.73 (0.37 to 1.46$)$ & 0.38 \\
\hline Obese III v. normal weight & 0.86 (0.40 to 1.85$)$ & 0.70 \\
\hline \multicolumn{3}{|l|}{ Postoperative medical events* } \\
\hline Overweight v. normal weight & 1.12 (0.69 to 1.82$)$ & 0.64 \\
\hline Obese I v. normal weight & 1.10 (0.66 to 1.85$)$ & 0.70 \\
\hline Obese II v. normal weight & 1.07 (0.57 to 2.01$)$ & 0.84 \\
\hline Obese III v. normal weight & 1.16 (0.54 to 2.48$)$ & 0.70 \\
\hline \multicolumn{3}{|l|}{ Required blood transfusion* } \\
\hline Overweight v. normal weight & $0.71(0.60$ to 0.83$)$ & $<0.001$ \\
\hline Obese I v. normal weight & $0.48(0.40$ to 0.58$)$ & $<0.001$ \\
\hline Obese II v. normal weight & $0.40(0.31$ to 0.51$)$ & $<0.001$ \\
\hline Obese III v. normal weight & $0.38(0.28$ to 0.52$)$ & $<0.001$ \\
\hline \multicolumn{3}{|l|}{ Readmission within 30 days* } \\
\hline Overweight v. normal weight & 0.88 (0.66 to 1.17$)$ & 0.37 \\
\hline Obese I v. normal weight & 1.07 (0.80 to 1.43$)$ & 0.65 \\
\hline Obese II v. normal weight & 1.64 (1.19 to 2.25$)$ & 0.002 \\
\hline Obese III v. normal weight & 1.59 (1.10 to 2.31$)$ & 0.014 \\
\hline \multicolumn{3}{|l|}{ Deep infection* } \\
\hline Overweight v. normal weight & $2.53(1.05$ to 6.12$)$ & 0.039 \\
\hline Obese I v. normal weight & $3.98(1.66$ to 9.54$)$ & 0.002 \\
\hline Obese II v. normal weight & 7.65 (3.15 to 18.58$)$ & $<0.001$ \\
\hline Obese III v. normal weight & 8.51 (3.37 to 21.48 ) & $<0.001$ \\
\hline \multicolumn{3}{|l|}{$\begin{array}{l}\text { Discharge to acute care, subacute } \\
\text { care or long-term care facility* }\end{array}$} \\
\hline Overweight v. normal weight & $0.94(0.78$ to 1.12$)$ & 0.48 \\
\hline Obese I v. normal weight & 1.07 (0.88 to 1.30$)$ & 0.48 \\
\hline Obese II v. normal weight & $1.72(1.37$ to 2.16$)$ & $<0.001$ \\
\hline Obese III v. normal weight & 3.16 (2.44 to 4.08$)$ & $<0.001$ \\
\hline \multicolumn{3}{|c|}{$\begin{array}{l}\mathrm{Cl}=\text { confidence interval; } \mathrm{OR}=\text { odds ratio. } \\
\text { *Adjusted for age, sex and presurgical risk factors using multiple logistic regression. }\end{array}$} \\
\hline
\end{tabular}

Patients who were overweight or who had class I, II or III obesity were more likely to have a deep infection than patients with normal BMI (overweight OR 2.53, 95\% CI 1.05 to 612 ; class I obesity OR $3.98,95 \%$ CI 1.66 to 9.54 ; class II obesity OR $7.65,95 \%$ CI 3.15 to 18.58 ; class III obesity OR $8.51,95 \%$ CI 3.37 to 21.48 ) (Table 2).

Patients with class II obesity (OR 1.72, 95\% CI 1.37 to 2.16) and class III obesity (OR 3.16, 95\% CI 2.44 to 4.08 ) were less likely to be discharged home than patients whose BMI was in the normal weight range (Table 2). Patients with class II and class III obesity had longer acute hospital stays $(4.3 \mathrm{~d})$ than patients who were classified as being of normal weight $(4.0 \mathrm{~d})$ or overweight $(4.0 \mathrm{~d})$ or who had class I obesity (3.9 d) ( $p<0.001)$ (Table 3$)$. After adjusting for sex, age and number of presurgical risk factors, we found that patients with class II and class III obesity had a shorter acute length of stay than patients in the normal weight group (difference of $0.42 \mathrm{~d}$ for patients with class II obesity and $0.50 \mathrm{~d}$ for patients with class III obesity) $(p<0.001)$ (Table 4$)$.
Table 3. Unadjusted acute length of stay after total hip arthroplasty

\begin{tabular}{|lcc|}
\hline Weight class & $\begin{array}{c}\text { Unadjusted acute length } \\
\text { of stay, } d, \text { mean } \pm \mathrm{SD}\end{array}$ & p value* \\
\hline Normal weight & $4.0 \pm 2.2$ & $<0.001$ \\
\hline Overweight & $4.0 \pm 3.5$ & \\
\hline Obese I & $3.9 \pm 2.4$ \\
\hline Obese II & $4.3 \pm 3.5$ \\
\hline Obese III & $4.3 \pm 2.9$ \\
\hline $\begin{array}{l}\text { SD }=\text { standard deviation. } \\
{ }^{*} \text { Calculated by analysis of variance. }\end{array}$ & \\
\hline
\end{tabular}

Table 4. Comparison of adjusted acute length of stay after total hip arthroplasty

\begin{tabular}{lcc|}
\hline Comparison & $\begin{array}{c}\text { Adjusted acute length of stay, d, } \\
\text { difference }(95 \% \mathrm{Cl})\end{array}$ & $p$ value* \\
\hline $\begin{array}{l}\text { Overweight v. normal } \\
\text { weight }\end{array}$ & $0.07(-0.09$ to 0.23$)$ & 0.38 \\
\hline $\begin{array}{l}\text { Obese I v. normal weight } \\
\begin{array}{l}\text { Obese II v. normal } \\
\text { weight }\end{array}\end{array}$ & $0.03(-0.14$ to 0.20$)$ & 0.72 \\
\hline $\begin{array}{l}\text { Obese III v. normal } \\
\text { weight }\end{array}$ & $0.42(0.22$ to 0.62$)$ & $<0.001$ \\
\hline $\begin{array}{l}\text { Cl }=\text { confidence interval. } \\
{ }^{*} \text { Adjusted for age, sex and presurgical risk factors using multiple linear regression. }\end{array}$
\end{tabular}

\section{Total knee arthroplasty}

The patient demographics for TKA are shown in Table 5 . A total of 16485 patients who underwent knee arthroplasty were included in this study (10 057 women, 6428 men). Of these patients, $91.9 \%$ were either overweight or had class I, II, or III obesity according to the WHO classification. More men than women were classified as overweight or as having class I obesity, but more women than men were classified as having class II or class III obesity. There was an inverse relationship between age at intervention and classification of obesity $(p<0.001)$. Patients with a BMI of $30 \mathrm{~kg} / \mathrm{m}^{2}$ or greater required a TKA 2.7 years earlier than patients of normal weight, patients with a BMI of $35 \mathrm{~kg} / \mathrm{m}^{2}$ or greater required a TKA 4.6 years earlier than patients whose weight was in the normal range, and patients whose BMI was $40 \mathrm{~kg} / \mathrm{m}^{2}$ or greater required a TKA 7.6 years earlier than patients of normal weight. Patients with class III obesity were more likely to have 2 or more presurgical risk factors than patients classified as being of normal weight $(51.0 \%$ v. $43.9 \%)(p<0.001)$.

Obesity classification had no effect on in-hospital postoperative periprosthetic fracture or dislocation (Table 6). Patients classified as overweight, class I obese, class II obese or class III obese all had lower rates of blood transfusion $(10.4 \%, 7.7 \%, 6.4 \%$ and $4.7 \%$, respectively) than patients who were of normal weight (15.1\%). Patients with class I, class II and class III obesity were more likely to have postoperative medical events than patients classified as being of normal weight (class I obesity OR 2.25, 


\begin{tabular}{|c|c|c|c|c|c|c|}
\hline \multirow[b]{2}{*}{ Characterisic } & \multicolumn{5}{|c|}{ Patients; weight class } & \multirow[b]{2}{*}{$p$ value } \\
\hline & $\begin{array}{c}\text { Normal weight } \\
\quad n=1331\end{array}$ & $\begin{array}{c}\text { Overweight } \\
n=4574\end{array}$ & $\begin{array}{c}\text { Class I obese } \\
n=4901\end{array}$ & $\begin{array}{c}\text { Class II obese } \\
n=3124\end{array}$ & $\begin{array}{c}\text { Class III obese } \\
n=2555\end{array}$ & \\
\hline Age, mean, yr & 70.3 & 69.2 & 67.6 & 65.7 & 62.7 & $<0.001^{*}$ \\
\hline \multicolumn{7}{|l|}{ Sex, no. (\%) } \\
\hline Male & $408(30.7)$ & $2043(44.7)$ & 2123 (43.3) & 1112 (35.6) & $742(29.0)$ & $<0.001 \dagger$ \\
\hline Female & $923(69.3)$ & $2531(55.3)$ & $2778(56.7)$ & 2012 (64.4) & $1813(71.0)$ & \\
\hline \multicolumn{7}{|c|}{ Presurgical risk factors, no. (\%) } \\
\hline 0 & 345 (25.9) & $1308(28.6)$ & $1374(28.0)$ & 807 (25.8) & $581(22.7)$ & $<0.001 \dagger$ \\
\hline 1 & $402(30.2)$ & $1376(30.1)$ & $1398(28.5)$ & $911(29.2)$ & $669(26.2)$ & \\
\hline$\geq 2$ & $584(43.9)$ & $1890(41.3)$ & 2130 (43.5) & $1407(45.0)$ & $1305(51.1)$ & \\
\hline
\end{tabular}

95\% CI 1.39 to 3.64 ; class II obesity OR $2.28,95 \%$ CI 1.38 to 3.75 ; class III obesity OR 2.05 , $95 \%$ CI 1.21 to 3.46). There was no difference in 30-day readmission rates among the different classifications of BMI. Patients

\begin{tabular}{|c|c|c|}
\hline Outcome; comparison & OR $(95 \% \mathrm{Cl})$ & $p$ value \\
\hline \multicolumn{3}{|l|}{ In-hospital fracture or dislocation* } \\
\hline Overweight v. normal weight & $1.11(0.23$ to 5.37$)$ & 0.90 \\
\hline Obese I v. normal weight & $1.48(0.32$ to 6.81$)$ & 0.62 \\
\hline Obese II v. normal weight & 0.68 (0.11 to 4.14$)$ & 0.68 \\
\hline Obese III v. normal weight & $1.62(0.31$ to 8.38$)$ & 0.56 \\
\hline \multicolumn{3}{|l|}{ Postoperative medical events* } \\
\hline Overweight v. normal weight & 1.49 (0.91 to 2.44$)$ & 0.11 \\
\hline Obese I v. normal weight & 2.25 (1.39 to 3.64$)$ & 0.001 \\
\hline Obese II v. normal weight & $2.28(1.38$ to 3.75$)$ & 0.001 \\
\hline Obese III v. normal weight & 2.05 (1.21 to 3.46$)$ & 0.007 \\
\hline \multicolumn{3}{|l|}{ Required blood transfusion* } \\
\hline Overweight v. normal weight & 0.77 (0.64 to 0.92$)$ & 0.004 \\
\hline Obese I v. normal weight & $0.58(0.48$ to 0.70$)$ & $<0.001$ \\
\hline Obese II v. normal weight & $0.48(0.39$ to 0.60$)$ & $<0.001$ \\
\hline Obese III v. normal weight & $0.37(0.29$ to 0.47$)$ & $<0.001$ \\
\hline \multicolumn{3}{|l|}{ Readmission within 30 days* } \\
\hline Overweight v. normal weight & 0.84 (0.62 to 1.14$)$ & 0.26 \\
\hline Obese I v. normal weight & $0.82(0.61$ to 1.11$)$ & 0.20 \\
\hline Obese II v. normal weight & $0.78(0.56$ to 1.09$)$ & 0.15 \\
\hline Obese III v. normal weight & $1.07(0.76$ to 1.50$)$ & 0.70 \\
\hline \multicolumn{3}{|l|}{ Deep infection* } \\
\hline Overweight v. normal weight & $0.61(0.26$ to 1.41$)$ & 0.25 \\
\hline Obese I v. normal weight & $0.72(0.32$ to 1.61$)$ & 0.42 \\
\hline Obese II v. normal weight & 1.05 (0.46 to 2.41$)$ & 0.90 \\
\hline Obese III v. normal weight & $2.00(0.01$ to 4.44$)$ & 0.049 \\
\hline \multicolumn{3}{|l|}{$\begin{array}{l}\text { Discharge to acute care, subacute } \\
\text { care or long-term care facility* }\end{array}$} \\
\hline Overweight v. normal weight & 0.83 (0.67 to 1.02$)$ & 0.08 \\
\hline Obese I v. normal weight & $0.93(0.75$ to 1.15$)$ & 0.51 \\
\hline Obese II v. normal weight & $1.34(1.07$ to 1.68$)$ & 0.012 \\
\hline Obese III v. normal weight & 2.57 (2.03 to 3.24$)$ & $<0.001$ \\
\hline
\end{tabular}

with class III obesity were more likely to have a deep infection than patients with normal BMI (OR 2.00, 95\% CI 0.01 to 4.44$)$.

Patients with class III obesity were more likely to have a longer acute length of stay in hospital than patients with normal BMI (OR 2.57, 95\% CI 2.03 to 3.24). Patients with class II or class III obesity were less likely to be discharged home than patients with normal BMI classification (class II obesity OR 1.34, 95\% CI 1.07 to 1.68 ; class III obesity OR 2.57, 95\% CI 2.03 to 3.24 ).

Patients classified as having class III obesity had a longer acute length of hospital stay than patients who were considered overweight or who had class 1 or II obesity (normal weight $4.2 \mathrm{~d}$, overweight $4.0 \mathrm{~d}$, class I obesity $3.9 \mathrm{~d}$, class II obesity 4.0 d, class III obesity 4.3 d) $(p<0.001)$ (Table 7). After adjusting for sex, age and number of presurgical risk factors, we found that patients with class III obesity had a shorter acute length of stay than patients with normal weight (difference $0.43 \mathrm{~d}, 95 \%$ CI 0.25 to 0.61) $(p<0.001)($ Table 8).

\section{Discussion}

Understanding the effect of elevated BMI on elective TKA and THA is critical to the evaluation of patients preoperatively. Counselling overweight and obese patients preoperatively about the increased risks they face is an important health advocate role of orthopedic surgeons. Our study highlights several factors that need to be considered when offering TKA and THA to obese patients.

Similar to other studies in the literature, we found that the majority of our patients undergoing THA and TKA had a BMI greater than $25 \mathrm{~kg} / \mathrm{m}^{2}$ and were considered overweight or obese. Bourne and colleagues ${ }^{3}$ found that $75 \%$ of patients undergoing THA and $88 \%$ of patients undergoing TKA in their study were overweight or obese, whereas over half of the general Canadian population is in these weight classes. 


\begin{tabular}{|c|c|c|}
\hline Weight class & $\begin{array}{l}\text { Unadjusted acute length } \\
\text { of stay, } d \text {, mean } \pm S D\end{array}$ & $p$ value* \\
\hline Normal weight & $4.2 \pm 2.5$ & $<0.001$ \\
\hline Overweight & $4.0 \pm 2.7$ & \\
\hline Obese I & $3.9 \pm 2.0$ & \\
\hline Obese II & $4.0 \pm 2.2$ & \\
\hline Obese III & $4.3 \pm 4.4$ & \\
\hline $\begin{array}{l}\mathrm{SD}=\text { standard deviation. } \\
{ }^{*} \text { Analysis of variance. }\end{array}$ & & \\
\hline
\end{tabular}

\begin{tabular}{|c|c|c|}
\hline Comparison & $\begin{array}{l}\text { Adjusted acute length of stay, } \\
\text { d, difference }(95 \% \mathrm{Cl})\end{array}$ & $p$ value* \\
\hline $\begin{array}{l}\text { Overweight v. } \\
\text { normal weight }\end{array}$ & $-0.09(-0.25$ to 0.07$)$ & 0.31 \\
\hline $\begin{array}{l}\text { Obese I v. } \\
\text { normal weight }\end{array}$ & $-0.09(-0.24$ to 0.08$)$ & 0.30 \\
\hline $\begin{array}{l}\text { Obese II v. } \\
\text { normal weight }\end{array}$ & $0.01(-0.16$ to 0.19$)$ & 0.89 \\
\hline $\begin{array}{l}\text { Obese III v. } \\
\text { normal weight }\end{array}$ & 0.43 (0.25 to 0.61$)$ & $<0.001$ \\
\hline \multicolumn{3}{|c|}{$\begin{array}{l}\mathrm{Cl}=\text { confidence interval. } \\
{ }^{*} \text { Adjusted for age, sex and presurgical risk factors using multiple linear regression }\end{array}$} \\
\hline
\end{tabular}

Similar to Gandhi and colleagues, ${ }^{10}$ we found that patients with high BMI required THA and TKA at an earlier age than patients of normal weight. The discrepancy in the age at which patients required TJA was more pronounced in the study by Gandhi and colleagues, with patients with a BMI of $35 \mathrm{~kg} / \mathrm{m}^{2}$ or greater requiring THA 7.1 years and TKA 7.9 years earlier than patients whose $\mathrm{BMI}$ was in the normal range.

There is a paucity of information in the literature regarding the association of BMI with presurgical risk factors. In patients 60 years of age and younger, Tohidi and colleagues found a $50 \%$ higher 10 -year risk of death in patients who presented with a BMI greater than $45 \mathrm{~kg} / \mathrm{m}^{2}{ }^{2}{ }^{16}$ In our study, patients with a BMI of $35 \mathrm{~kg} / \mathrm{m}^{2}$ or greater in the THA cohort and a BMI of $40 \mathrm{~kg} / \mathrm{m}^{2}$ or greater in the TKA cohort were more likely than patients whose weight was in the normal range to have more than 2 presurgical medical risk factors. This is certainly not surprising, as the literature has repeatedly demonstrated that surgical patients with increasing $\mathrm{BMI}$ are at a greater risk of presenting with more medical comorbidities. ${ }^{17-19}$

Our study did not find that increasing BMI had any effect on acute in-hospital mechanical complications (periprosthetic fracture or dislocation). A meta-analysis by Kerkhoffs and colleagues did not find a relationship between obesity and an increased risk of early fracture. ${ }^{20}$

In our THA cohort, we did not find that patients with increased BMI were at risk of developing postoperative in-hospital medical complications. This was not true for the TKA cohort. In our TKA cohort, patients whose $B M I$ was $30 \mathrm{~kg} / \mathrm{m}^{2}$ or greater were more likely to have postoperative in-hospital medical complications, including deep vein thrombosis, pulmonary embolism and myocardial infarction. We were surprised to not find an increase in in-hospital medical complications among obese patients in the THA cohort, as other literature demonstrates that increased BMI is a significant risk factor for the development of postsurgical medical complications. ${ }^{20-23}$

Consistent with the literature,,$^{20,22,24,25}$ our TKA and THA cohorts with BMI greater than or equal to $40 \mathrm{~kg} / \mathrm{m}^{2}$ had an increased risk of periprosthetic infection. Alvi and colleagues ${ }^{4}$ recently found that patients whose BMI was in this range were 3.32 times more likely to develop a deep wound infection after THA.

The literature is mixed with respect to the effect of obesity on length of stay for patients who undergo THA and TKA. In our THA cohort, patients had a longer length of stay when their BMI was $35 \mathrm{~kg} / \mathrm{m}^{2}$ or greater. In our TKA cohort, patients had a longer length of stay when their BMI was $40 \mathrm{~kg} / \mathrm{m}^{2}$ or greater. Kessler and colleagues ${ }^{26}$ and Alvi and colleagues ${ }^{4}$ both showed that BMI does not affect length of stay in the population undergoing THA, and Issa and colleaguees ${ }^{27}$ did the same in the population undergoing TKA. Rajgopal and colleagues ${ }^{9}$ were able to demonstrate an increased length of stay after THA in patients whose BMI was $40 \mathrm{~kg} / \mathrm{m}^{2}$ or greater.

In both our THA and TKA cohorts, we found that BMI greater than or equal to $25 \mathrm{~kg} / \mathrm{m}^{2}$ was protective with respect to transfusion requirements. This is consistent with the most recent study in the literature. Frisch and colleagues ${ }^{28}$ found that in both THA and TKA, increased BMI was protective with respect to transfusion requirements; patients with higher BMI had an overall lower transfusion rate than patients with a BMI less than $25 \mathrm{~kg} / \mathrm{m}^{2}$. Although they found that obese patients lost more blood than matched normal-weight patients, they found that obese patients lost a lower percentage of their total blood volume, which resulted in a decreased need for transfusion.

We found that there was an increase in 30-day readmission rates in our THA cohort among patients whose BMI was $35 \mathrm{~kg} / \mathrm{m}^{2}$ or greater, but there was no such difference in our TKA cohort. Alvi and colleagues did not show that obesity had any effect on 30-day readmission rates in either THA or TKA, but a study that looked at hip surgery, knee surgery, colectomy and thoracotomy did show an increase in 30-day readmission rates once BMI reached $40 \mathrm{~kg} / \mathrm{m}^{2} .22$

In both our THA and TKA cohorts we found that patients with a BMI of $35 \mathrm{~kg} / \mathrm{m}^{2}$ or greater were less likely to go home directly from hospital; they tended to go first to a rehabilitation facility. To our knowledge, we were the first to look at discharge destination after THA 
and TKA. The finding that these patients have a statistically higher probability of not returning immediately to their place of permanent residence is an important financial consideration, especially given the current financial constraints facing our health care system.

\section{Limitations}

Limitations of this study include its retrospective design. Furthermore, we focused only on the acute medical and mechanical symptoms experienced by our patients in hospital. Given that we were able to capture only inhospital complications and medical events, adverse events might have been underreported. The ABJHI database is strengthened by the ability to capture any readmission within 30 days postoperatively for all causes in any hospital in the province of Alberta. However, any readmission outside the province of Alberta is not captured. Therefore, there may be a small number of readmissions outside of the province of Alberta in the first 30 days that were not captured in our data set. However, our robust study design, the prospective nature of the data in the database and the extremely large patient cohorts in both the total THA and TKA groups strengthen our findings.

\section{Conclusion}

The number of patients requiring THA and TKA continues to increase worldwide. At the same time, the obesity epidemic continues to factor into the overall success and failure of these surgical procedures. We found that patients with increased BMI who underwent THA or TKA had an increased number of in-hospital medical events, had an increased rate of deep infection and were less likely to be discharged home. Increasing BMI increased the rate of 30-day readmission and length of stay in the THA cohort but had no effect on the TKA population. Patients with a BMI of $30 \mathrm{~kg} / \mathrm{m}^{2}$ or greater required a THA 1.7 years earlier than patients whose weight was in the normal range, patients with a BMI of $35 \mathrm{~kg} / \mathrm{m}^{2}$ or greater needed a THA 3.4 years earlier, and patients whose BMI was $40 \mathrm{~kg} / \mathrm{m}^{2}$ or greater required a THA 5.8 years earlier. In the TKA cohort, patients with a BMI of $30 \mathrm{~kg} / \mathrm{m}^{2}$ or greater required a TKA 2.7 years earlier, those with a BMI of $35 \mathrm{~kg} / \mathrm{m}^{2}$ or greater required a TKA 4.6 years earlier, and patients with a BMI of $40 \mathrm{~kg} / \mathrm{m}^{2}$ or greater needed surgery 7.6 years earlier than patients of normal weight. This study provides some important surgical considerations when contemplating TJA in the obese population.

Affiliations: From the Cumming School of Medicine, University of Calgary, Calgary, Alta. (Abdulla, Mahdavi, Gill, Powell, Johnston, Sharma); and the Alberta Bone and Joint Health Institute, Calgary, Alta. (Khong).

\section{Competing interests: None declared.}

Contributors: I. Abdulla, S. Mahdavi, R. Gill, J. Powell, K. Johnston and R. Sharma designed the study. H. Khong acquired and analyzed the data. I. Abdulla and R. Sharma wrote the article, which all authors critically reviewed and approved for publication.

\section{References}

1. McCalden RW, Charron KD, MacDonald SJ, et al. Does morbid obesity affect the outcome of total hip replacement? I Bone foint Surg Br 2011;93:321-5.

2. Vasarhelyi EM, MacDonald SJ. The influence of obesity on total joint arthroplasty. 7 Bone foint Surg Br 2012;94:100-2.

3. Bourne R, Mukhi S, Zhu N, et al. Role of obesity on the risk for total hip or knee arthroplasty. Clin Orthop Relat Res 2007;465:185-8.

4. Alvi HM, Mednick RE, Krishnan V, et al. The effect of BMI on 30 day outcomes following total joint arthroplasty. 7 Arthroplasty 2015;30:1113-7.

5. Michalka PKR, Khan RJK, Scaddan MC, et al. The influence of obesity on early outcomes in primary hip arthroplasty. 7 Arthroplasty 2012;27:391-6.

6. Baker P, Petheram T, Jameson S, et al. The association between body mass index and the outcomes of total knee arthroplasty. 7 Bone foint Surg Am 2012;94:1501-8.

7. Collins RA, Walmsley PJ, Amin AK, et al. Does obesity influence clinical outcome at nine years following total knee replacement? 7 Bone foint Surg Br 2012;94:1351-5.

8. Davis AM, Wood AM, Keenan ACM, et al. Does body mass index affect clinical outcome post-operatively and at five years after primary unilateral total hip replacement performed for osteoarthritis? f Bone foint Surg Br 2011;93:1178-82.

9. Rajgopal R, Martin R, Howard JL, et al. Outcomes and complications of total hip replacement in super-obese patients. Bone foint 7 2013;95-B:758-63.

10. Gandhi R, Wasserstein D, Razak F, et al. BMI independently predicts younger age at hip and knee replacement. Obesity (Silver Spring) 2010;18:2362-6.

11. Raphael I, Parmar M, Mehrganpour N, et al. Obesity and operative time in primary total joint arthroplasty. 7 Knee Surg 2013;26:95-9.

12. Mnatzaganian G, Ryan P, Norman PE, et al. Total joint replacement in men: old age, obesity and in-hospital complications. ANZ 7 Surg 2013;83:376-81.

13. Issa K, McElroy MJ, Pourtaheri S, et al. Outcomes of primary total knee arthroplasty in the morbidly obese patients. 7 Long Term Eff Med Implants 2013;23:301-7.

14. Frank C, Dick D, Smith D, et al. The Alberta Bone and Joint Health Institute: creating sustainable accountability through collaboration, relevant measurement and timely feedback. Healthc Pap 2006;7:34-9.

15. Rusk A, Bush K, Brandt M, et al. Improving surveillance for surgical site infections following total hip and knee arthroplasty using diagnosis and procedure codes in a provincial surveillance network. Infect Control Hosp Epidemiol 2016;37:699-703.

16. Tohidi M, Brogly SB, Lajkosz K, et al. Ten-year mortality and revision after total knee arthroplasty in morbidly obese patients. $f$ Arthroplasty 2018;33:2518-23.

17. Must A, Spadano J, Coakley EH, et al. The disease burden associated with overweight and obesity. FAMA 1999;282:1523-9.

18. Field AE, Coakley EH, Must A, et al. Impact of overweight on the risk of developing common chronic diseases during a 10-year period. Arch Intern Med 2001;161:1581-6.

19. Kim Y, Morshed S, Joseph T, et al. Clinical impact of obesity on stability following revision total hip arthroplasty. Clin Orthop Relat Res 2006;453:142-6. 
20. Kerkhoffs GM, Servien E, Dunn W, et al. The influence of obesity on the complication rate and outcome of total knee arthroplasty: a meta-analysis and systematic literature review. 7 Bone foint Surg Am 2012;94:1839-44.

21. Mnatzaganian G, Ryan P, Norman PE, et al. Total joint replacement in men: old age, obesity and in-hospital complications. ANZ 7 Surg 2013;83:376-81.

22. Silber JH, Rosenbaum PR, Kelz RR, et al. Medical and financial risks associated with surgery in the elderly obese. Ann Surg 2012;256:79-86.

23. Jain NB, Guller U, Pietrobon R, et al. Comorbidities increase complication rates in patients having arthroplasty. Clin Orthop Relat Res 2005;435:232-8.

24. Dowsey MM, Choong PFM. Obesity is a major risk factor for prosthetic infection after primary hip arthroplasty. Clin Orthop Relat Res 2008;466:153-8.

25. Namba RS, Paxton L, Fithian DC, et al. Obesity and perioperative morbidity in total hip and total knee arthroplasty patients. 7 Arthroplasty 2005;20:46-50.

26. Kessler S, Käfer W. Overweight and obesity: Two predictors for worse early outcome in total hip replacement? Obesity (Silver Spring) 2007;15:2840-5

27. Issa K, Pivec R, Kapadia BH, et al. Does obesity affect the outcomes of primary total knee arthroplasty? 7 Knee Surg 2013;26:89-94.

28. Frisch N, Wessell NM, Charters M, et al. Effect of body mass index on blood transfusion in total hip and knee arthroplasty. Orthopedics 2016;39:e844-9. 